\title{
Sleep and Work Functioning in Nurses Undertaking Inpatient Shifts in a Blue-Depleted Light Environment
}

\section{Kaia Kjørstad}

Norwegian University of Science and Technology

Patrick M. Faaland

Norwegian University of Science and Technology

\section{Børge Sivertsen}

Norwegian Institute of Public Health

\section{Håvard Kallestad}

Norwegian University of Science and Technology

Knut Langsrud

St. Olavs University Hospital

\section{Daniel Vethe}

Norwegian University of Science and Technology

Cecilie L. Vestergaard

Norwegian University of Science and Technology

\section{Anette Harris}

University of Bergen

\section{Ståle Pallesen}

University of Bergen

Jan Scott

Newcastle University

Øystein Vedaa ( $\nabla$ Oystein.Vedaa@fhi.no)

Norwegian University of Science and Technology

\section{Research Article}

Keywords: Blue-depleted Light Environment, Hospital Lighting, Shift Work, Sleep, Work Function

Posted Date: February 10th, 2022

DOI: https://doi.org/10.21203/rs.3.rs-1297960/v1 
License: (c) (i) This work is licensed under a Creative Commons Attribution 4.0 International License. Read Full License 


\section{Abstract}

Background: Blue-depleted light environments (BDLEs) may in some cases benefit health outcomes for hospital inpatients. However, less is known about the effects on hospital staff. This study aimed to explore the effects of a BDLE compared with a standard hospital light environment (STLE) in a naturalistic setting on nurses' functioning during shifts and sleep patterns between shifts.

Methods: Twenty-five nurses recruited from St. Olavs Hospital in Trondheim, Norway, completed 14 days of actigraphy recordings and self-reported assessments of sleep (e.g., total sleep time/sleep efficiency) and functioning while at work (e.g., mood, stress levels/caffeine use) in two different light conditions. Additionally, participants were asked to complete several validated scales and questionnaires to assess symptoms on medical conditions, mental health conditions, and side effects associated with the light conditions.

Results: A multilevel fixed-effects regression model showed a within-subject increase in subjective sleepiness (by 17\%) during evening shifts in BDLE compared with STLE ( $p=.034$; Cohen's $d=0.49$ ) and an 0.2 increase in number of caffeinated beverages during nightshifts in STLE compared with BDLE ( $p=$ .027; Cohen's $d=0.37$ ). There were no significant differences neither on subjective or objective sleep measures, nor on self-reported levels of stress or mood across the two conditions. Exploratory betweengroups analyses of questionnaire data showed that there were no significant differences except that nurses working in BDLE reported that the lighting was perceived as warmer $(p=.009)$ and more relaxing $(p=.023)$ than nurses working in STLE.

Conclusions: Overall, there was little evidence that the changed light condition had any negative impact on nurses' sleep and function, despite some indication of increased evening sleepiness in BDLE. We recommend further investigations on this topic before BDLEs are implemented as standard solutions in healthcare institutions and propose specific suggestions for designing future large-scale trials and cohort studies.

Trial registration: The study was registered before data collection was completed on the ISRCTN website (ISRCTN21603406).

\section{Background}

Exposure to light and darkness over the course of a day is the major cue for entrainment of sleep and wakefulness in humans (1). However, in modern societies, humans are frequently exposed to artificial light sources during the dark period (evenings and nights) of the day. Artificial, or polychromatic white light, has been found to aid vision and enhance alertness and performance at night $(2,3)$. Simultaneously, it is well-established that exposure to artificial light can compromise the rhythmicity and timing of individual sleep- and wakefulness patterns and thus cause e.g., sleep problems, medical problems, and mental health problems (4). This is especially important for shift workers who regularly need to be awake and active during the dark period of the day and who subsequently need to sleep or rest during the light 
part of the day. Such rest-activity patterns are associated with an increased risk of e.g., insomnia or shift work disorder (5-7), cardiovascular disease (8,9), cancer (10-13), gastro-intestinal disorders (14), metabolic disturbances (15), diabetes (16-18), and impaired reproductive health (19-21), as well having adverse effects on mental health $(4,22,23)$ and the work-life balance $(24)$.

Shift work is particularly common in the healthcare sector where 24-hour services are necessary to provide needed and required health services (25). Given the critical need to provide medical care around the clock, it is not surprising that hospital inpatients experience disruptions in their sleep-wake cycles and typically sleep poorly e.g., due to elevated levels of light and noise $(26,27)$. In recent years, several clinical and research groups have advocated the installation of blue-depleted light environments (BDLEs; indoor lighting blocking short-frequency, blue light $<530 \mathrm{~nm}$ ) to counteract the effects of artificial light exposure at night and help stabilize the sleep-wake patterns of hospital inpatients with positive effects being reported following such interventions $(28,29)$. Likewise, a study on healthy adults residing in a BDLE found positive effects on sleep without any adverse effects or side effects (30).

Recently, a new acute psychiatric unit was built at St. Olavs Hospital, Østmarka, in Trondheim, Norway (latitude $\sim 63^{\circ} \mathrm{N}$ ) and new lighting systems were installed. The unit consisted of two inpatient wards. One ward allowed for the introduction of a BDLE during evenings and nights whereas the other ward always had a standard hospital lighting environment (STLE). This was primarily done to investigate the effects of evening and night BDLE on sleep and recovery time for patients admitted to the hospital (31). However, in this regard it is highly warranted also to investigate whether exposure to a BDLE represent any benefit or harm to the nurses engaged in shift work under such conditions. To our knowledge, no previous studies have explored whether working in a BDLE compared with a STLE impacts work performance and/or well-being of nurses in a naturalistic setting. The main aim of the present study was therefore to use subjective (work and sleep diaries) and objective (actigraphy) recordings to investigate nurses' sleep patterns, work functioning, levels of stress, and mood state over a 2-week period during which they undertook shifts in a BDLE and a STLE, respectively. Additionally, we explored nurses' self-reported physical and mental health when working in each light condition.

\section{Methods}

\section{Study Design and Participants}

The present study was originally designed as a non-randomized 12-week cross-over trial (ISRCTN21603406). The aim was to investigate the effects of evening and night BDLE compared with STLE in a sample of nursing staff (nurses and nurse assistants - from now on referred to as nurses) working shifts in an acute psychiatric unit at St. Olavs Hospital. The unit was built as two separate wards with mirror-image layouts each consisting of 20 patient rooms and common areas. In one of the wards, both light fixtures and incident light were depleted of blue light frequencies $(<530 \mathrm{~nm})$ from 18:30 to 07:00 hours, whereas the other ward always had standard hospital lighting. Light measurements demonstrated that the lighting in the two wards had similar levels of photopic lux but that the levels of 
melanopic lux were lower in the BDLE than in the STLE. Details of the layout, the light system and the light measurements are thoroughly described elsewhere (30). The nurses could not change the lighting manually in any of the light conditions and during daytime both units had similar light environments.

Nurses employed at the acute psychiatric unit at St. Olavs Hospital when the study started in November 2018 were invited to participate if they currently worked at least $50 \%$ of fulltime equivalent. Based on this criterion, 25 of 106 employees were excluded from participation because they were on leave (e.g., maternity leave or sick leave). As such, the sample comprised a convenience sample of nurses $(n=86)$ studied in their natural work setting. Study-participation was voluntary. When data collection began, one half of the nursing staff worked in the unit with BDLE and the other half in the unit with STLE. The order of the conditions was not randomized due to a pre-set work schedule. Some nurses were permanently assigned to work night shifts, whereas others rotated between day and evening shifts, or worked weekends only.

Of the 86 nurses who met the inclusion criteria, 25 (29.1\%) agreed to participate and signed an informed consent form before participating in the study and provided data for the first 6 weeks of data collection (either working in BDLE or STLE). After 3 weeks of working in each light condition, participants were asked to complete questionnaires and to keep a work- and sleep diary for 2 weeks. After the cross-over (week 6 to 12 of the study), 10 (11.7\%) participants provided data from the other light condition (either BDLE or STLE). Actigraphy data were collected from 23 of 25 participants during the first 6 weeks of data collection and from 8 of 10 participants in the last 6 weeks of data collection.

The study was designed and implemented by external researchers (i.e., not employed at the acute psychiatric unit at St. Olavs Hospital) in response to concerns raised by nurses and safety representatives about possible negative side effects of working in a BDLE. The topic was generally discussed with employees in the acute psychiatric unit through informational meetings and one-on-one meetings (e.g., between a nurse and a safety representative or a nurse and management) throughout the planning period, and both nurses and safety representatives were closely involved in the development of the present study. Anonymity was strictly implemented to protect the privacy of those who chose to participate. As such, we do not know why the participation rate was not higher. Due to the comparatively

small sample size, we were limited in the analyses we were able to conduct, and we were not able to carry out the investigation based on a cross-over design.

\section{Ethics}

The study protocol was approved by the Regional Ethical Committee of Central Norway (REK reference number: 2018/1516). The study was registered 28/12/2018 on the ISRCTN website (ISRCTN21603406).

Assessments

- Demographic and background variables - Information was collected regarding sex, age, height and weight, cohabitation status, whether the nurses had children living at home, number of years worked 
as nursing staff, and percentage of full time equivalent.

- Work Diary - The work diary comprised 10 questions to gather data on the day-to-day shift schedule of the participants for 14 consecutive days: the date of the shift, and work hours. They were also asked to report number of caffeinated beverages consumed during each shift (e.g., coffee, tea, energy drinks), levels of sleepiness (from not at all sleepy (1) to very sleepy (5)), stress (from not at all stressed (1) to very stressed (5)), and mood, i.e., positive feelings (from not at all positive (1) to very positive (5)) and negative feelings (from not at all negative (1) to very negative (5)).

- Sleep Diary - Sleep was assessed by a sleep diary (32) to provide subjective, daily estimates of sleep episodes for 14 consecutive days (in parallel with the work diary). The following measures were derived from the diary: Time in Bed (TIB), Sleep Period Time (SPT; duration of the sleep period); Total Sleep Time (TST), Sleep Onset Latency (SOL), Wake After Sleep Onset (WASO), Early Morning Awakening (EMA; time spent in bed after final wake-up time), Sleep Efficiency (SE; total sleep time as a percentage of time in bed), number of awakenings, and an overall rating of the sleep quality from 1 (very restless) through 5 (very sound).

- Actigraphy - Motor activity was assessed using actigraphy data collected with GENEActive® actiwatches for 14 consecutive days to derive the following estimates: Wake After Sleep Onset (WASO), Total Sleep Time (TST), Sleep Period Time (SPT; time between falling asleep and the final awakening), and number of sleep periods (SIBS). The actiwatch data was processed and scored using the GGIR package (version 2.2-1) (33-35) for R (version 3.6.2). The GGIR sleep-detection algorithm was used to identify sleep onset and wakeup-times and to score sleep and wakefulness between these timepoints. Due to a high proportion of daytime sleep in the shift-working participants, and often multiple sleep periods within 24 hours, the scored actigraphy output was manually compared with participants' sleep diaries to correct obvious error estimates by the software. Where obvious discrepancies between sleep diaries and actigraphy appeared, the sleep diary data was used.

- Questionnaire data - Participants were asked to complete several validated scales and questionnaires to assess symptoms on medical conditions, mental health conditions, and side effects associated with the light conditions. Specifically: the Kessler Psychological Distress Scale (K10; used to identify adults with varying levels of psychological distress) (36), a short version of the Psychological Health Questionnaire (PHQ; to assess sleep disturbances, headaches, respiratory infections, and gastrointestinal problems) (37), the Headache and Eyestrain Scale (H\&ES; to assess eye strain and headache) (38), an Evaluation about beliefs about the light condition (BAL; rating pleasantness and color of the lighting) (39), one additional item probing the experienced adequacy of the lighting in a work setting ('unsuitable for work - suitable for work'), one item assessing work strain, three items assessing performance and effort from the Psychological Variables Questionnaire (40), 12 items assessing negative side effects of the light conditions (31), and the Brief Horne-Östberg Morningness-Eveningness Questionnaire (MEQ; to assess chronotype) (41). 
Fixed-effects regression models were fitted to capture the within subject effects, using methods of maximum likelihood estimation in STATA, version 17. Sleep- and work diary data, and actigraphy data, were structured so that each participant was compared with themselves in terms of how they sleep and function across the two different light conditions. Sleep periods that started within 15 hours after a shift ended was included in the analyses. As previously mentioned, the participants kept diaries and wore an actiwatch for approximately 14 days in each light condition and had typically had $\sim 5$ shifts during this time. By structuring the data this way, each participant contributed multiple observations across the two light conditions (168 shifts in total), giving the study an acceptable statistical power. Results are shown separately for comparison done for evening BDLE compared with evening STLE, night BDLE compared with night STLE, and evening and night BDLE combined compared with evening and night STLE combined. Additionally, mean values for each light condition, estimated mean difference, confidence intervals ( $\mathrm{Cl} ; 95 \%)$, and effects sized in terms of Cohen's $d$ are shown. Cohen's $d$ was calculated in line with recognized guidelines $(42,43)$. As a benchmark for interpreting Cohen's $d, 0.80$ is regarded as large, 0.50 as moderate, and 0.20 as small (44), respectively.

Due to the limited sample size of the present study, analyses performed on outcome variables from the questionnaires (i.e., outcomes without multiple observations) should be regarded as exploratory. One-way between groups ANOVAs were performed using IBM SPSS Statistics, version 25 to examine differences in medical and mental health for participants working in the BDLE compared with the STLE during the first round of data collection (data from the second round was excluded due to the inadequate sample size).

\section{Results}

\section{Sample characteristics}

The nurses included in the study had a mean age of 39.9 years ( $S D=12.3$ years), was predominantly female (83.3\%), about half were married/cohabitating (54.1\%) and/or had children living at home (54.1\%). On average they worked $89.2 \%(S D=14.4 \%$ ) of full-time equivalent and had nearly ten years of work experience as nurses ( $m e a n=9.4$ years; $S D=7.7$ years).

\section{Differences between blue-depleted and standard hospital light environments}

Table 1 shows results from the fixed effects linear models comparing the BDLE with the STLE on the outcome variables. Analyses of the work diaries showed within subject differences of increased subjective sleepiness (by 17\%) during evening shifts in BDLE compared with STLE ( $p=.034$; Cohen's $d=$ 0.49 ) and a 0.2 increase in number of caffeinated beverages consumed during nights in STLE compared with BDLE ( $\mathrm{p}=.027$; Cohen's $d=0.37)$. There were no differences in terms of stress levels, or positive and negative feelings during shifts ( $p$-values ranging from .246 to .943). Sleep diary data indicated no differences on any of the outcome variables (TIB, TST, SOL, WASO, EMA, SE, number of awakenings, or sleep quality; p-values ranging from .206 to .991). On actigraphy data, we found no differences on any of the outcome variables (TST, WASO, SPT or SIBS; p-values ranging from .129 to .949) between conditions. 
Given the limited sample size available, exploratory one-way between groups ANOVAs were performed on items extracted from the self-rated questionnaires (i.e., outcomes without multiple observations).

Supplementary Table 1 shows means and standard deviations for these variables for all participants and then categorized according to light condition. There were no significant differences between the groups except that nurses working in BDLE reported that the lighting was perceived as warmer $(p=.009)$ and more relaxing $(p=.023)$ than nurses in STLE.

Table 1. Results from fixed effects linear models comparing the effects of BDLE with STLE. 


\section{Mean Mean Estimated \\ STLE BDLE mean \\ 95\% Cl $\underset{\text { Value }}{\mathrm{P}} \stackrel{\text { Cohen's }}{ }$ \\ Difference}

\section{Work Diary}

Number of Caffeinated drinks
Evs $\mathrm{E}$
2.15
1.19
0.21
-0.42 to
$0.508 \quad 0.636$
0.84
$\mathrm{N}$ vs $\mathrm{N}$
2.11
$1.73-0.37$
-0.70 to
$\mathbf{0 . 0 2 7 *} 0.367$
$-0.04$
E.N. vs E.N.
2.14
1.49
$-0.09$
-0.42 to
0.24
$0.582 \quad 0.490$

How stressful was your shift?

(range 1-5) ${ }^{a}$

\begin{tabular}{|c|c|c|c|c|c|c|}
\hline E vs $E$ & 2.56 & 2.31 & -0.32 & $\begin{array}{l}-0.92 \text { to } \\
0.27\end{array}$ & 0.277 & 0.225 \\
\hline $\mathrm{N}$ vs $\mathrm{N}$ & 2.95 & 2.70 & -0.30 & $\begin{array}{l}-0.88 \text { to } \\
0.28\end{array}$ & 0.312 & 0.248 \\
\hline E.N. vs E.N. & 2.74 & 2.53 & -0.24 & $\begin{array}{l}-0.65 \text { to } \\
0.17\end{array}$ & 0.246 & 0.202 \\
\hline
\end{tabular}

How sleepy were you during the shift? (range 1-5) ${ }^{a}$

Evs $\mathrm{E}$

$\mathrm{N}$ vs $\mathrm{N}$

E.N. vs E.N.

How positive did you feel during the shift? (range 1-5) ${ }^{a}$

E vs $\mathrm{E}$

$\mathrm{N}$ vs N

E.N. vs E.N.

3.55
$2.46 \quad 3.03$

0.74

0.06 to

1.42

$\begin{array}{lll}2.86 & 3.07 & 0.22\end{array}$

-0.34 to

0.77

$2.65 \quad 3.06$

0.42 


\begin{tabular}{|c|c|c|c|c|c|c|}
\hline & $\begin{array}{l}\text { Mean } \\
\text { STLE }\end{array}$ & $\begin{array}{l}\text { Mean } \\
\text { BDLE }\end{array}$ & $\begin{array}{l}\text { Estimated } \\
\text { mean } \\
\text { Difference }\end{array}$ & $95 \% \mathrm{Cl}$ & $\begin{array}{l}\mathrm{P} \\
\text { Value }\end{array}$ & $\begin{array}{l}\text { Cohen's } \\
d\end{array}$ \\
\hline Evs $E$ & 1.62 & 1.63 & 0.10 & $\begin{array}{l}-0.45 \text { to } \\
0.65\end{array}$ & 0.723 & -0.011 \\
\hline $\mathrm{N}$ vs $\mathrm{N}$ & 1.70 & 1.57 & -0.09 & $\begin{array}{l}-0.46 \text { to } \\
0.28\end{array}$ & 0.619 & 0.194 \\
\hline E.N. vs E.N. & 1.66 & 1.60 & -0.01 & $\begin{array}{l}-0.32 \text { to } \\
0.30\end{array}$ & 0.943 & 0.076 \\
\hline \multicolumn{7}{|l|}{ Sleep Diary } \\
\hline \multicolumn{7}{|l|}{ Time in Bed, min } \\
\hline Evs $E$ & 507.00 & 481.00 & 31.47 & $\begin{array}{l}-198.37 \\
\text { to } \\
261.30\end{array}$ & 0.785 & 0.088 \\
\hline $\mathrm{N}$ vs $\mathrm{N}$ & 488.00 & 529.00 & 98.99 & $\begin{array}{l}-177.39 \\
\text { to } \\
375.37\end{array}$ & 0.476 & -0.104 \\
\hline E.N. vs E.N. & 499.00 & 508.00 & 73.34 & $\begin{array}{l}-102.50 \\
\text { to } \\
249.17\end{array}$ & 0.410 & -0.025 \\
\hline \multicolumn{7}{|c|}{ Sleep Period Time, min } \\
\hline Evs $E$ & 410.00 & 405.00 & -18.19 & $\begin{array}{l}-70.74 \text { to } \\
34.37\end{array}$ & 0.491 & 0.074 \\
\hline $\mathrm{N}$ vs $\mathrm{N}$ & 361.00 & 399.00 & 65.30 & $\begin{array}{l}-45.14 \text { to } \\
175.73\end{array}$ & 0.241 & -0.238 \\
\hline E.N. vs E.N. & 390.00 & 401.00 & 34.18 & $\begin{array}{l}-28.13 \text { to } \\
96.48\end{array}$ & 0.279 & -0.093 \\
\hline \multicolumn{7}{|c|}{ Total Sleep Time, min } \\
\hline Evs E & 356.00 & 371.00 & -7.57 & $\begin{array}{l}-61.88 \text { to } \\
46.74\end{array}$ & 0.781 & -0.203 \\
\hline $\mathrm{N}$ vs $\mathrm{N}$ & 328.00 & 376.00 & 6.11 & $\begin{array}{l}-41.30 \text { to } \\
173.52\end{array}$ & 0.223 & -0.314 \\
\hline E.N. vs E.N. & 344.00 & 374.00 & 39.25 & $\begin{array}{l}-21.84 \text { to } \\
100.33\end{array}$ & 0.206 & -0.239 \\
\hline \multicolumn{7}{|c|}{ Sleep Onset Latency, min } \\
\hline Evs $E$ & 23.31 & 24.54 & -3.09 & $\begin{array}{l}-20.29 \text { to } \\
14.11\end{array}$ & 0.720 & -0.046 \\
\hline
\end{tabular}




\begin{tabular}{|c|c|c|c|c|c|c|}
\hline & $\begin{array}{c}\text { Mean } \\
\text { STLE }\end{array}$ & $\begin{array}{l}\text { Mean } \\
\text { BDLE }\end{array}$ & $\begin{array}{l}\text { Estimated } \\
\text { mean } \\
\text { Difference }\end{array}$ & $95 \% \mathrm{Cl}$ & $\begin{array}{l}\mathrm{P} \\
\text { Value }\end{array}$ & $\begin{array}{l}\text { Cohen's } \\
d\end{array}$ \\
\hline $\mathrm{N}$ vs $\mathrm{N}$ & 14.68 & 8.85 & -2.25 & $\begin{array}{l}-13.15 \text { to } \\
8.65\end{array}$ & 0.680 & 0.334 \\
\hline E.N. vs E.N. & 19.64 & 15.94 & -2.82 & $\begin{array}{l}-12.32 \text { to } \\
6.67\end{array}$ & 0.557 & 0.162 \\
\hline \multicolumn{7}{|c|}{ Wake After Sleep Onset, min } \\
\hline Evs $E$ & 34.07 & 9.11 & -10.80 & $\begin{array}{l}-34.95 \text { to } \\
13.36\end{array}$ & 0.374 & 0.804 \\
\hline $\mathrm{N}$ vs $\mathrm{N}$ & 18.65 & 13.62 & 1.43 & $\begin{array}{l}-14.32 \text { to } \\
17.19\end{array}$ & 0.856 & 0.194 \\
\hline E.N. vs E.N. & 27.43 & 11.58 & -3.58 & $\begin{array}{l}-17.08 \text { to } \\
9.92\end{array}$ & 0.600 & 0.537 \\
\hline \multicolumn{7}{|c|}{ Early Morning Awakening, min } \\
\hline E vs $E$ & 15.74 & 11.04 & -5.02 & $\begin{array}{l}-16.61 \text { to } \\
6.57\end{array}$ & 0.389 & 0.287 \\
\hline $\mathrm{N}$ vs $\mathrm{N}$ & 67.68 & 114.00 & 54.63 & $\begin{array}{l}-129.70 \\
\text { to } \\
238.96\end{array}$ & 0.555 & -0.172 \\
\hline E.N. vs E.N. & 37.50 & 67.68 & 28.12 & $\begin{array}{l}67.21 \text { to } \\
123.45\end{array}$ & 0.560 & -0.156 \\
\hline \multicolumn{7}{|c|}{ Sleep Efficiency, \% } \\
\hline E vs $E$ & 77.84 & 83.83 & 0.66 & $\begin{array}{l}11.48 \text { to } \\
12.80\end{array}$ & 0.913 & -0.378 \\
\hline $\mathrm{N}$ vs $\mathrm{N}$ & 78.31 & 79.79 & 0.09 & $\begin{array}{l}-11.44 \text { to } \\
11.63\end{array}$ & 0.987 & -0.083 \\
\hline E.N. vs E.N. & 78.03 & 81.61 & 0.67 & $\begin{array}{l}-7.39 \text { to } \\
8.73\end{array}$ & 0.870 & -0.214 \\
\hline \multicolumn{7}{|c|}{ Nightly Awakenings, No. } \\
\hline Evs $E$ & 1.60 & 1.39 & -0.41 & $\begin{array}{l}-1.26 \text { to } \\
0.44\end{array}$ & 0.336 & 0.152 \\
\hline $\mathrm{N}$ vs $\mathrm{N}$ & 1.26 & 1.35 & 0.38 & $\begin{array}{l}-0.37 \text { to } \\
1.12\end{array}$ & 0.313 & -0.068 \\
\hline E.N. vs E.N. & 1.45 & 1.37 & 0.05 & $\begin{array}{l}-0.50 \text { to } \\
0.59\end{array}$ & 0.864 & 0.060 \\
\hline Sleep Quality ${ }^{a}$ & & & & & & \\
\hline
\end{tabular}




\begin{tabular}{|c|c|c|c|c|c|c|}
\hline & $\begin{array}{l}\text { Mean } \\
\text { STLE }\end{array}$ & $\begin{array}{c}\text { Mean } \\
\text { BDLE }\end{array}$ & $\begin{array}{l}\text { Estimated } \\
\text { mean } \\
\text { Difference }\end{array}$ & $95 \% \mathrm{Cl}$ & $\begin{array}{l}\mathrm{P} \\
\text { Value }\end{array}$ & $\begin{array}{l}\text { Cohen's } \\
d\end{array}$ \\
\hline Evs $E$ & 3.05 & 3.48 & 0.23 & $\begin{array}{l}-0.65 \text { to } \\
1.11\end{array}$ & 0.601 & -0.397 \\
\hline $\mathrm{N}$ vs $\mathrm{N}$ & 3.29 & 3.29 & $<0.00$ & $\begin{array}{l}-0.52 \text { to } \\
0.52\end{array}$ & 0.991 & 0.000 \\
\hline E.N. vs E.N. & 3.15 & 3.38 & 0.10 & $\begin{array}{l}-0.37 \text { to } \\
0.57\end{array}$ & 0.671 & -0.243 \\
\hline \multicolumn{7}{|l|}{ Actigraphy } \\
\hline \multicolumn{7}{|c|}{ Sleep Period Time, min } \\
\hline Evs E & 410.00 & 402.00 & 11.65 & $\begin{array}{l}-48.65 \text { to } \\
71.95\end{array}$ & 0.698 & 0.123 \\
\hline $\mathrm{N}$ vs $\mathrm{N}$ & 369.00 & 389.00 & 67.18 & $\begin{array}{l}-53.89 \text { to } \\
188.26\end{array}$ & 0.269 & -0.135 \\
\hline E.N. vs E.N. & 393.00 & 395.00 & 53.19 & $\begin{array}{l}-15.89 \text { to } \\
122.28\end{array}$ & 0.129 & -0.020 \\
\hline \multicolumn{7}{|c|}{ Total Sleep Time, min } \\
\hline Evs E & 362.00 & 345.00 & 1.86 & $\begin{array}{l}-56.37 \text { to } \\
60.09\end{array}$ & 0.949 & 0.283 \\
\hline $\mathrm{N}$ vs $\mathrm{N}$ & 342.00 & 366.00 & 68.88 & $\begin{array}{l}-42.37 \text { to } \\
180.13\end{array}$ & 0.218 & -0.329 \\
\hline E.N. vs E.N. & 353.00 & 356.00 & 50.30 & $\begin{array}{l}-14.77 \text { to } \\
115.37\end{array}$ & 0.128 & -0.221 \\
\hline \multicolumn{7}{|c|}{ Wake After Sleep Onset, min } \\
\hline Evs $E$ & 52.00 & 57.24 & 7.72 & $\begin{array}{l}-16.28 \text { to } \\
31.70\end{array}$ & 0.518 & -0.131 \\
\hline $\mathrm{N}$ vs $\mathrm{N}$ & 26.55 & 22.89 & -1.79 & $\begin{array}{l}-22.26 \text { to } \\
18.67\end{array}$ & 0.860 & 0.126 \\
\hline E.N. vs E.N. & 40.57 & 39.40 & 2.15 & $\begin{array}{l}-12.57 \text { to } \\
16.86\end{array}$ & 0.772 & 0.031 \\
\hline \multicolumn{7}{|c|}{ Sleep Periods, No. } \\
\hline Evs E & 14.10 & 13.79 & -2.23 & $\begin{array}{l}-5.13 \text { to } \\
0.68\end{array}$ & 0.130 & 0.070 \\
\hline $\mathrm{N}$ vs $\mathrm{N}$ & 11.67 & 11.76 & 1.64 & $\begin{array}{l}-2.86 \text { to } \\
6.14\end{array}$ & 0.464 & -0.017 \\
\hline
\end{tabular}




\begin{tabular}{|c|c|c|c|c|c|c|}
\hline & $\begin{array}{c}\text { Mean } \\
\text { STLE }\end{array}$ & $\begin{array}{c}\text { Mean } \\
\text { BDLE }\end{array}$ & $\begin{array}{l}\text { Estimated } \\
\text { mean } \\
\text { Difference }\end{array}$ & $95 \% \mathrm{Cl}$ & $\begin{array}{l}\mathrm{P} \\
\text { Value }\end{array}$ & $\begin{array}{l}\text { Cohen's } \\
d\end{array}$ \\
\hline E.N. vs E.N. & 13.10 & 12.84 & 0.13 & $\begin{array}{l}-2.45 \text { to } \\
2.71\end{array}$ & 0.919 & 0.053 \\
\hline \multicolumn{7}{|c|}{ 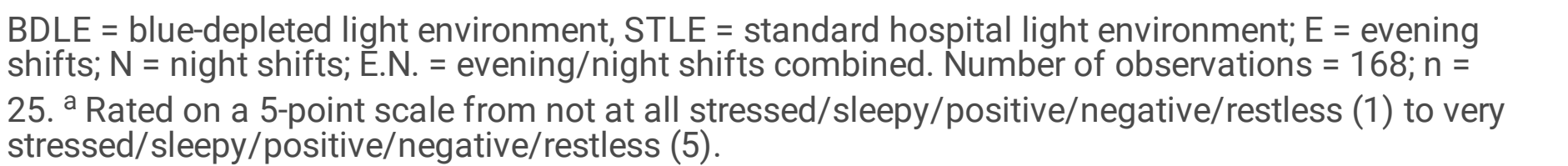 } \\
\hline
\end{tabular}

\section{Discussion}

The main aim of the present study was to investigate the effects of a BDLE compared with a STLE in an acute psychiatric unit at St. Olavs Hospital on shift working nurses' sleep, mood, levels of stress, and caffeine use. To the best of our knowledge, this is the first study to examine how nurses experience working in a BDLE compared with a STLE. Overall, the results showed that most aspects of the nurses' sleep and functioning were unchanged by exposure to the two light conditions. However, the nurses reported higher levels of sleepiness during evening shifts in the BDLE than in the STLE. In addition, nurses reported consuming a slightly higher number of caffeinated beverages during night shifts in the STLE than in the BDLE.

The fact that subjective sleepiness was higher during evening shifts in BDLE makes sense considering that lower levels of white light exposure during the evening (when it is becoming gradually darker outside), is associated with lower levels of melatonin suppression (45). Melatonin is a hormone that helps the body to know when it's time to sleep and wake up, and melatonin suppression is associated with shifting of the circadian phase so that sleepiness and sleep occur later in the day $(46,47)$. At least a partial circadian adaptation to night shifts might be desirable, since it could potentially increase job performance and reduce the risk of accidents at work or in commute, as well as improve daytime sleep during days off work when nurses must re-adapt to a daytime schedule (48-50). We did not find support for differing adaptation to shift work between the light conditions, but the lower levels of evening sleepiness is STLE likely reflects that white light has a direct activating effect, e.g., by increasing alertness $(3,38,39)$. As such, increased sleepiness in BDLE may compromise the nurses' safety, e.g., if they need to react instantly to adverse events. Further, it is comparably surprising that we did not find the same increase in sleepiness during night shifts in the BDLE. One explanation may be that the study does not have statistical power to detect e.g., small within-subject effects of BDLE compared with STLE. Another possible explanation may be the ceiling effect, in which the level of sleepiness during the night shift was high in both light conditions, and that the measurement of sleepiness used in this study is not well enough suited to distinguish between the nuances in the levels of sleepiness.

Our research group previously conducted a pilot study with 12 healthy adults using a randomized crossover design comparing the effects of a BDLE with a STLE on e.g., sleep, subjective sleepiness, and the 
experience of side effects (30). In that study, the effects of the BDLE were generally positive. Participants did not report higher levels of sleepiness or negative side effects, the participants' sleep-wake cycle was phase-advanced (i.e., higher levels of melatonin earlier at night) and they slept marginally longer (8.1 minutes) after residing in the BDLE. One explanation for our contradictory finding of increased sleepiness during evening shifts in BDLE could be the difference between assessments, i.e., hourly ratings of sleepiness from 19:00 to 23:00 versus global assessment of sleepiness during whole shifts retrospectively. Alternatively, differences in demands made on participants just residing in the building compared with nurses performing work-related tasks could further impact to what extent an individual experiences fatigue and sleepiness. Additionally, in the present study, we did not find significant differences on any sleep outcomes after working in BDLE compared with STLE, which might also be explained by the difference between assessments (i.e., polysomnography data versus diary- and actigraphy data), or that artificial light exposure when commuting home from work and at home before bedtime is sufficient to reverse subtle effects of a BDLE at work (51-53).

We also found a small 0.2 increase in number of caffeinated beverages consumed when undertaking night shifts in the STLE compared with the BDLE. While interesting, the available data do not allow us to determine whether this is best explained by differences in energy levels or perceived alertness during night shifts in different light conditions or individual fluctuation in caffeine intake (related to spurious factors), etc. Interestingly, we found no differences between BDLE and STLE on nurses' reported levels of stress, positive or negative mood during shifts, or sleep patterns after each shift was completed. This was unexpected given that shift work is a known risk factor for e.g., poor sleep (5), medical or mental health problems (4), and impaired attention and alertness during waking hours (54). Some of the negative effects of shift work can generally be attributed to suboptimal shifting of the circadian phase (55). However, as light can be used to shift the circadian phase to better adapt to night work (56), we might expect BDLE, or 'virtual darkness' $(57,58)$, to have a different effect on nurses' sleep and functioning in a naturalistic setting than STLE. In many respects, the limited number of macro-level differences between the light conditions is encouraging as it indicates that a BDLE is not associated with major side effects or harmful effects. However, these findings need to be confirmed in further studies before BDLEs can be assumed to be beneficial to patients but not harmful to clinical staff working in inpatient units.

\section{Limitations and future directions}

There are some important limitations of the present study that should be mentioned. Due to the comparatively small sample size, we were limited in the types of analyses we were able to conduct. Further, we did not perform any correction for multiple comparisons (e.g., by adjusting for false discovery rate (59)) as this, with our limited sample size, would have increased the risk of false negatives. Failure to detect e.g., side effects of the light conditions would be potentially harmful to the nurses. A larger sample size is important for e.g., reliable, and meaningful multivariable analysis on the effects of a BDLE compared with a STLE on nurses' sleep, health, and functioning or effects of switching between light conditions. A larger sample size would also facilitate analysis of whether the BDLE effects the nurses' circadian rhythms directly and the impact of possible confounding factors (e.g., if patients exposed to 
BDLE were calmer and as such influenced the nurses). The within-subject design in a naturalistic setting is a strength of the present study but due to the low participation rate $(29.1 \%)$, we cannot ascertain that our findings are representative of all nurses working at the acute psychiatric unit at St. Olavs Hospital. Although other single-site studies in small workplaces (less than $~ 100$ employees) also necessarily will be bound by an upper limit of available participants, ensuring high participation rates would make sure that any drawn conclusions will be representative of all employees. Additionally, use of employer- or registry data in futures studies, as opposed to self-report, could both ease time demands on the participants and be a source of objective, high quality information on how shift working nurses are affected by a BDLE. Such sources could be used to collect information on e.g., sickness absence, other types of leave, health care resource use, and medical or mental health diagnoses. They will not, however, be suitable to investigate individual experiences of day-to-day life, and important information on e.g., personal experiences in and of the work environment, levels of presenteeism (i.e., reduced productivity while at work), impairment in general activities outside of work, or subclinical symptoms of medical or mental health conditions.

\section{Conclusion}

Our study suggests that working in a BDLE does not considerably impact the nurses' sleep, levels of stress or mood in a naturalistic setting. There was some indication that the light environments may affect the nurses' functioning during shifts. Limitations of the present study put restrictions on the analyses we were able to conduct and the conclusions that can be drawn. We are, however, optimistic that BDLEs in hospitals are acceptable to the nurses. We recommend further investigations on this topic before BDLEs are implemented as standard solutions in healthcare institutions, and we have proposed specific suggestions for designing future large-scale trials and cohort studies.

\section{Abbreviations}

BAL - Evaluation about the beliefs about the light condition

BDLE - Blue-depleted light environment

EMA - Early Morning Awakening

H\&ES - Headache and Eyestrain Scale

K10 - The Kessler Psychological Distress Scale

MEQ - Morningness-Eveningness Questionnaire

PHQ - Psychological Health Questionnaire

REK - Regional Ethical Committee of Central Norway 
SE - Sleep Efficiency

SIBS - number of sleep periods

SOL - Sleep Onset Latency

SPT - Sleep Period Time

STLE - Standard hospital light environment

TIB - Time in Bed

TST - Total Sleep Time

WASO - Wake After Sleep Onset

\section{Declarations}

\section{Ethics approval and consent to participate}

The study was conducted in accordance with the Declaration of Helsinki and approved by the Regional Ethical Committee of Central Norway (REK reference number: 2018/516). Written informed consent was obtained from all subjects involved in the study.

Consent for publication

Not applicable.

Availability of data and materials

The datasets generated and analyzed during the current study are not publicly available as we do not have ethical approval for this type of data sharing.

Competing interests

The authors declare that they have no competing interests.

\section{Funding}

This research was funded by the Dam Foundation for Health and Rehabilitation; project number 2018/F0198760.

Authors' contributions

Conceptualization, K.K, H.K., K.L. and Ø.V.; methodology, K.K., A.H., S.P. and Ø.V.; formal analysis, K.K. and $\varnothing$. .; investigation, K.K. and P.F.; data curation, K.K., P.F. and D.V.; writing-original draft preparation, K.K.; 
writing-review and editing, P.F., B.S., K.L., D.V., C.V., A.H., S.P., J.S. and Ø.V.; project administration, K.L. and $\varnothing$.V.; funding acquisition, K.K. All authors have read and agreed to the published version of the manuscript.

\section{Acknowledgements}

The authors would like to thank head nurse Egil Sandø, research nurse Kjetil Sørensen and other members of the nursing staff at St. Olavs Hospital for their contributions to the trial.

\section{References}

1. Wirz-Justice A. How to Measure Circadian Rhythms in Humans. Mediographia. 2007;29(1):7.

2. Badia P, Myers B, Boecker M, Culpepper J, Harsh JR. Bright light effects on body temperature, alertness, EEG and behavior. Physiology \& Behavior. 1991 Sep;50(3):583-8.

3. Souman JL, Tinga AM, te Pas SF, van Ee R, Vlaskamp BNS. Acute alerting effects of light: A systematic literature review. Behavioural Brain Research. 2018 Jan;337:228- 39.

4. Vogel M, Braungardt T, Meyer W, Schneider W. The effects of shift work on physical and mental health. J Neural Transm. 2012 Oct;119(10):1121-32.

5. Åkerstedt T, Fredlund P, Gillberg M, Jansson B. Work load and work hours in relation to disturbed sleep and fatigue in a large representative sample. Journal of Psychosomatic Research. 2002 Jul;53(1):585-8.

6. Vedaa Ø, Mørland E, Larsen M, Harris A, Erevik E, Sivertsen B, et al. Sleep Detriments Associated With Quick Returns in Rotating Shift Work: A Diary Study. Journal of Occupational and Environmental Medicine. 2017 Jun;59(6):522-7.

7. Pallesen S, Bjorvatn B, Waage S, Harris A, Sagoe D. Prevalence of Shift Work Disorder: A Systematic Review and Meta-Analysis. Front Psychol. 2021 Mar 23;12(638252).

8. Vyas MV, Garg AX, lansavichus AV, Costella J, Donner A, Laugsand LE, et al. Shift work and vascular events: systematic review and meta-analysis. BMJ. 2012 Jul 26;345(e4800).

9. Torquati L, Mielke GI, Brown WJ, Kolbe-Alexander T. Shift work and the risk of cardiovascular disease. A systematic review and meta-analysis including dose- response relationship. Scand J Work Environ Health. 2018 May;44(3):229-38.

10. Costa G, Haus E, Stevens R. Shift work and cancer - considerations on rationale, mechanisms, and epidemiology. Scand J Work Environ Health. 2010 Mar;36(2):163- 79.

11. Manouchehri E, Taghipour A, Ghavami V, Ebadi A, Homaei F, Latifnejad Roudsari R. Night-shift work duration and breast cancer risk: an updated systematic review and meta-analysis. BMC Women's Health. 2021 Dec;21(89).

12. Sun C, Cheng C, Kozma K, Chandra G, Kim NH, Bhan C. Is shift-work associated with increased risk of rectal cancer? A meta-analysis. JCO [Internet]. 2021 May 20 [cited 2022 Jan 18];39(e15600).

Available from: https://ascopubs.org/doi/10.1200/JC0.2021.39.15_suppl.e15600 
13. Wang X, Ji A, Zhu Y, Liang Z, Wu J, Li S, et al. A meta-analysis including dose- response relationship between night shift work and the risk of colorectal cancer. Oncotarget. 2015 Sep;6(28):25046-60.

14. Knutsson A, Bøggild H. Gastrointestinal disorders among shift workers. Scand J Work Environ Health. 2010 Mar;36(2):85-95.

15. Gan $Y$, Yang $C$, Tong $X$, Sun $H$, Cong $Y$, Yin $X$, et al. Shift work and diabetes mellitus: a meta-analysis of observational studies. Occup Environ Med. 2015 Jan;72(1):72-8.

16. Morikawa Y, Nakagawa H, Miura K, Soyama Y, Ishizaki M, Kido T, et al. Shift work and the risk of diabetes mellitus among Japanese male factory workers. Scand J Work Environ Health. 2005 Jun;31(3):179-83.

17. Pan A, Schernhammer ES, Sun Q, Hu FB. Rotating Night Shift Work and Risk of Type 2 Diabetes: Two Prospective Cohort Studies in Women. Groop L, editor. PLoS Med. 2011 Dec 6;8(12).

18. Li W, Chen Z, Ruan W, Yi G, Wang D, Lu Z. A meta-analysis of cohort studies including dose-response relationship between shift work and the risk of diabetes mellitus. Eur J Epidemiol. 2019 Nov;34(11):1013-24.

19. Bonzini M, Coggon D, Palmer KT. Risk of prematurity, low birthweight and pre- eclampsia in relation to working hours and physical activities: a systematic review. Occupational and Environmental Medicine. 2006 Dec 20;64(4):228-43.

20. Nurminen T. Shift and reproductive health. 1998;24(3):28-34.

21. Stocker LJ, Macklon NS, Cheong YC, Bewley SJ. Influence of Shift Work on Early Reproductive Outcomes: A Systematic Review and Meta-analysis. Obstetrics \& Gynecology. 2014 Jul;124(1):99110.

22. Torquati L, Mielke GI, Brown WJ, Burton NW, Kolbe-Alexander TL. Shift Work and Poor Mental Health: A Meta-Analysis of Longitudinal Studies. Am J Public Health. 2019 Nov;109(11):e13-20.

23. Haines III VY, Marchand A, Rousseau V, Demers A. The mediating role of work-to- family conflict in the relationship between shiftwork and depression. Work \& Stress. 2008 Oct;22(4):341-56.

24. Kunst JR, Løset GK, Hosøy D, Bjorvatn B, Moen BE, Magerøy N, et al. The Relationship Between Shift Work Schedules and Spillover in a Sample of Nurses. International Journal of Occupational Safety and Ergonomics. 2014 Jan;20(1):139-47.

25. Parent-Thirion A, European Foundation for the Improvement of Living and Working Conditions, editors. Fourth European working conditions survey. Luxembourg: Office for Offical Publ. of the European Communities; 2007. 134 p. (EF).

26. Boyko $Y$, Jennum P, Nikolic M, Holst R, Oerding H, Toft P. Sleep in intensive care unit: The role of environment. Journal of Critical Care. 2017 Feb;37:99-105.

27. Elliott R, McKinley S, Cistulli P. The quality and duration of sleep in the intensive care setting: An integrative review. International Journal of Nursing Studies. 2011 Mar;48(3):384-400.

28. Sasseville A, Paquet N, Sevigny J, Hebert M. Blue blocker glasses impede the capacity of bright light to suppress melatonin production. J Pineal Res. 2006 Aug;41(1):73-8. 
29. van der Lely S, Frey S, Garbazza C, Wirz-Justice A, Jenni OG, Steiner R, et al. Blue Blocker Glasses as a Countermeasure for Alerting Effects of Evening Light-Emitting Diode Screen Exposure in Male Teenagers. Journal of Adolescent Health. 2015 Jan;56(1):113-9.

30. Vethe D, Scott J, Engstrøm M, Salvesen $\varnothing$, Sand T, Olsen A, et al. The evening light environment in hospitals can be designed to produce less disruptive effects on the circadian system and improve sleep. Sleep. 2020 Sep 21;

31. Kallestad H, Vedaa $\varnothing$, Scott J, Morken G, Pallesen S, Harvey AG, et al. Overcoming insomnia: protocol for a large-scale randomised controlled trial of online cognitive behaviour therapy for insomnia compared with online patient education about sleep. BMJ Open. 2018 Aug;8(8):e025152.

32. Carney CE, Buysse DJ, Ancoli-Israel S, Edinger JD, Krystal AD, Lichstein KL, et al. The Consensus Sleep Diary: Standardizing Prospective Sleep Self-Monitoring. Sleep. 2012 Feb;35(2):287-302.

33. Migueles JH, Rowlands AV, Huber F, Sabia S, van Hees VT. GGIR: A Research Community-Driven Open Source R Package for Generating Physical Activity and Sleep Outcomes From Multi-Day Raw Accelerometer Data. Journal for the Measurement of Physical Behaviour. 2019 Sep 1;2(3):188-96.

34. van Hees VT, Fang Z, Langford J, Assah F, Mohammad A, da Silva ICM, et al. Autocalibration of accelerometer data for free-living physical activity assessment using local gravity and temperature: an evaluation on four continents. Journal of Applied Physiology. 2014 Oct 1;117(7):738-44.

35. van Hees VT, Sabia S, Jones SE, Wood AR, Anderson KN, Kivimäki M, et al. Estimating sleep parameters using an accelerometer without sleep diary. Sci Rep. 2018 Dec;8(1):12975.

36. Kessler RC, Barker PR, Colpe LJ, Epstein JF, Gfroerer JC, Hiripi E, et al. Screening for Serious Mental Illness in the General Population. Arch Gen Psychiatry. 2003 Feb 1;60(2):184.

37. Schat ACH, Kelloway EK, Desmarais S. The Physical Health Questionnaire (PHQ): Construct Validation of a Self-Report Scale of Somatic Symptoms. Journal of Occupational Health Psychology. 2005 Oct;10(4):363-81.

38. Viola AU, James LM, Schlangen LJ, Dijk D-J. Blue-enriched white light in the workplace improves selfreported alertness, performance and sleep quality. Scand J Work Environ Health. 2008 Aug;34(4):297-306.

39. Smolders KCHJ, de Kort YAW. Bright light and mental fatigue: Effects on alertness, vitality, performance and physiological arousal. Journal of Environmental Psychology. 2014 Sep;39:77-91.

40. Pilcher JJ, Walters AS. How Sleep Deprivation Affects Psychological Variables Related to College Students' Cognitive Performance. Journal of American College Health. 1997 Nov;46(3):121-6.

41. Adan A, Almirall H. Horne \& Ôstberg Morningness-Eveningness Questionnaire: A Reduced Scale. Personality and Individual Differences. 1991;(12):241-53.

42. Carlson KD, Schmidt FL. Impact of Experimental Design on Effect Size: Findings From the Research Literature on Training. Journal of Applied Psychology. 1999;86(6):851-62.

43. Morris SB. Estimating Effect Sizes From Pretest-Posttest-Control Group Designs. Organizational Research Methods. 2008 Apr;11(2):364-86. 
44. Cohen J. Statistical power analysis for the behavioral sciences. 2nd ed. Hillsdale, N.J: L. Erlbaum Associates; $1988.567 \mathrm{p}$.

45. van de Werken M, Giménez MC, de Vries B, Beersma DGM, Gordijn MCM. Short- wavelength attenuated polychromatic white light during work at night: limited melatonin suppression without substantial decline of alertness. Chronobiology International. 2013 Aug;30(7):843-54.

46. Czeisler C, Allan J, Strogatz S, Ronda J, Sanchez R, Rios C, et al. Bright light resets the human circadian pacemaker independent of the timing of the sleep-wake cycle. Science. 1986 Aug 8;233(4764):667-71.

47. Lewy AJ, Sack RL, Miller LS, Hoban TM. Antidepressant and Circadian Phase- Shifting Effects of Light. Science. 1987;235:352-3.

48. Åkerstedt T, Kecklund G, Hörte L-G. Night Driving, Season, and the Risk of Highway Accidents. Sleep. 2001 Jun;24(4):401-6.

49. Boudreau P, Dumont GA, Boivin DB. Circadian Adaptation to Night Shift Work Influences Sleep, Performance, Mood and the Autonomic Modulation of the Heart. Bartell PA, editor. PLoS ONE. 2013 Jul 26;8(7):e70813.

50. Dinges DF. An overview of sleepiness and accidents. Journal of Sleep Research. 1995;4(2):4-14.

51. Gooley JJ, Chamberlain K, Smith KA, Khalsa SBS, Rajaratnam SMW, Van Reen E, et al. Exposure to Room Light before Bedtime Suppresses Melatonin Onset and Shortens Melatonin Duration in Humans. The Journal of Clinical Endocrinology \& Metabolism. 2011 Mar 1;96(3):E463-72.

52. Martin JS, Laberge L, Sasseville A, Bérubé M, Alain S, Lavoie J, et al. Timely use of in-car dim blue light and blue blockers in the morning does not improve circadian adap. 2021;16.

53. Prayag AS, Najjar RP, Gronfier C. Melatonin suppression is exquisitely sensitive to light and primarily driven by melanopsin in humans. J Pineal Res. 2019 May;66(4):e12562.

54. Åkerstedt T. Work hours, sleepiness and the underlying mechanisms. Journal of Sleep Research. 1995;4(2):15-22.

55. Arendt J. Shift work: coping with the biological clock. Occupational Medicine. 2010 Jan 1;60(1):1020.

56. Bjorvatn B, Kecklund Gör, Åkerstedt T. Bright light treatment used for adaptation to night work and readaptation back to day life. A field study at an oil platform in the North Sea. Journal of Sleep Research. 1999 Jun;8(2):105-12.

57. Gottlieb JF, Benedetti F, Geoffroy PA, Henriksen TEG, Lam RW, Murray G, et al. The chronotherapeutic treatment of bipolar disorders: A systematic review and practice recommendations from the ISBD task force on chronotherapy and chronobiology. Bipolar Disord. 2019 Dec;21(8):741-73.

58. Henriksen TE, Skrede S, Fasmer OB, Schoeyen H, Leskauskaite I, Bjørke- Bertheussen J, et al. Blueblocking glasses as additive treatment for mania: a randomized placebo-controlled trial. Bipolar Disord. 2016 May;18(3):221-32. 
59. Benjamini Y, Hochberg Y. Controlling the False Discovery Rate: A Practical and Powerful Approach to Multiple Testing. Journal of the Royal Statistical Society: Series B (Methodological). 1995 Jan;57(1):289-300.

\section{Supplementary Files}

This is a list of supplementary files associated with this preprint. Click to download.

- Supplementarymaterial.docx 